Tropical Journal of Pharmaceutical Research June 2017; 16 (6): 1383-1390

ISSN: $1596-5996$ (print); 1596-9827 (electronic)

(C) Pharmacotherapy Group, Faculty of Pharmacy, University of Benin, Benin City, 300001 Nigeria.

All rights reserved.

Available online at http://www.tjpr.org

Original Research Article

http://dx.doi.org/10.4314/tjpr.v16i6.24

\title{
Enhanced antitumor activity of cabazitaxel targeting CD44+ receptor in breast cancer cell line via surface functionalized lipid nanocarriers
}

\author{
Chun-jiang Zhu and Chuan-guo An* \\ Department of Breast and Thyroid Surgery, People's Hospital of Rizhao, Shandong 276825, China
}

*For correspondence: Email: AnChuanguo1999@gmail.com; Tel/Fax: 0086-0633-3365069

Sent for review: 18 January 2016

Revised accepted: 7 May 2017

\begin{abstract}
Purpose: To investigate the properties of surface-functionalized, hyaluronic acid-coated, cabazitaxelloaded solid lipid nanoparticles (HA-CZ-SLNs) for the treatment of breast cancer.

Methods: HA-CZ-SLNs were prepared by a homogenization method. Nanoparticles were designed for prolonged circulation and slow release of the drug, as well as internalization of the nanocarrier into cancer cells. The nanoparticles were evaluated using dynamic light scattering, in vitro drug release, cell cytotoxicity and uptake studies.

Results: Transmission electron microscopy revealed the resultant particles to be distinct, discrete, spherical cores surrounded by HA shells with a uniform diameter of $210 \mathrm{~nm}$. In vitro release of $C Z$ followed a biphasic pattern with sustained release throughout the study period, implying efficient delivery for treatment. Increased cytotoxicity was exerted by HA-CZ-SLNs compared with the free drug. More importantly, HA on the surface of nanoparticles interacted with CD44 receptors overexpressed on cancer cells, resulting in increased internalization in MCF-7 cells. Excess free HA competed with this uptake, indicating that nanoparticle uptake was via receptor-mediated endocytosis. This mechanism is expected to result in enhanced therapeutic efficacy for the treatment of breast cancer.

Conclusion: The results indicate prolonged release and enhanced cell penetration, release and cytotoxicity of the drug, thus showing the potential application of the surface-modified nanoparticles for the treatment of breast cancer.
\end{abstract}

Keywords: Cabazitaxel, Breast cancer, Hyaluronic acid, Nanoparticle, Lipid carrier, Receptor-mediated endocytosis

Tropical Journal of Pharmaceutical Research is indexed by Science Citation Index (SciSearch), Scopus, International Pharmaceutical Abstract, Chemical Abstracts, Embase, Index Copernicus, EBSCO, African Index Medicus, JournalSeek, Journal Citation Reports/Science Edition, Directory of Open Access Journals (DOAJ), African Journal Online, Bioline International, Open-J-Gate and Pharmacy Abstracts

\section{INTRODUCTION}

Invasive breast cancer is the leading cause of cancer-related mortality among women worldwide [1]. More than 1.8 million cases per year are reported in Western countries, according to the Federal Research Institute for Health Organization and Informatics of the Ministry of Health (Russian Federation) and the International Agency for Research on Cancer $[2,3]$. Among the various therapies available, radiotherapy, surgery, and conventional chemotherapy are very effective for the clinical treatment of breast cancer [4,5]. Taxanes such as docetaxel and paclitaxel have been classified as first-line cancer therapy drugs [6,7]. However, due to poor survival rates, new drugs have been explored to provide more effective therapeutic strategies for breast cancer [8]. Cabazitaxel (CZ) is a second-generation taxane family member specifically designed for the treatment of solid tumors. CZ was approved in June 2010 by the 
US Food and Drug Administration for the treatment of cancer [9]. CZ is a hydrophobic drug that acts on microtubules, inducing G2/M cellcycle arrest, leading to cell death $[10,11]$. However, because of their poor solubility and severe side effects, taxanes require modification before use in the clinic, and many alternative biocompatible formulations have been designed to deliver taxane drugs more effectively and safely [12].

Among the various drug-delivery systems, solid lipid nanoparticles (SLNs) act as a potent carrier system for various pharmaceutical compounds. SLNs are considered ideal carrier polymers owing to their high biocompatibility and bioavailability. Their improved solubility and excellent stability result in controlled drug release, minimizing adverse effects and enhancing antitumor activity [13-15]. Further, surface modification of SLNs by site-specific targeting agents improves cellular internalization and selective targeting. In this context, we have used hyaluronic acid (HA), a hydrophilic, anionic, biodegradable, nontoxic polymer composed of $\beta$ 1,4-D-glucuronic acid-b-1,3-N-acetyl-Dglucosamine subunits. HA has biological properties such as muco-adhesiveness and receptor-mediated internalization via CD44 receptors, which activate some signaling pathways. CD44 is an integral membrane glycoprotein overexpressed on the cell surfaces of several tumor types compared with normal cells. These receptors are bound by highmolecular-weight HA and can be used to target cells with high tumorigenic potential $[16,17]$.

The objective of the present study was to develop unique HA-functionalized, CZ-loaded SLNs (HA-CZ-SLNs) with high tumor specificity, designed to mediate more efficient cellular uptake and to facilitate specific tumor-cell delivery of the anticancer drug via the CD44 receptor.

\section{EXPERIMENTAL}

\section{Materials}

CZ was supplied by the Shanghai Institute of Pharmaceutical Industry (Shanghai, China). Didecyldimethylammonium bromide (DDAB) and 3-[4,5-dimethylthiazol-2-yl]2,5-diphenyltetrazolium bromide (MTT) were purchased from Sigma (St. Louis, MO, USA). Dulbecco's Modified Eagle Medium (DMEM) high glucose was purchased from HyClone Thermo Scientific. (Logan, Waltham, USA) All chemicals were analytical grade and used without further purification.

\section{Preparation of HA-CZ-SLNs}

HA-CZ-SLNs were prepared by homogenization and sonication. Briefly, the lipid phase Compritol 888 ATO (250 mg), DDAB (30 mg), and CZ (10 $\mathrm{mg}$ ) were heated to $5-10^{\circ} \mathrm{C}$ above their melting points and melted completely. An aqueous solution containing tocopheryl polyethylene glycol succinate (TPGS, $100 \mathrm{mg}$ ) was preheated, added to the lipid phase, and homogenized (Ultra-Turrax homogenizer (IKA-Werke, Staufen Germany) for $5 \mathrm{~min}$ at $12000 \mathrm{rpm}$. The resulting pre-emulsion was probe sonicated for $5 \mathrm{~min}$ at $70 \%$ amplitude [18]. HA and SLN were prepared by an electrostatic attraction method, in which 1 $\mathrm{mL}$ of a $0.05 \%(\mathrm{w} / \mathrm{v}) \mathrm{HA}$ solution under vigorous stirring was added to a CZ-SLN dispersion at a 10:1 ratio for $15 \mathrm{~min}$ [19]. The final resulting suspension was freeze-dried and stored at $4{ }^{\circ} \mathrm{C}$.

\section{Assessments of the particle size (PS), polydispersity index (PDI), and zeta potential (ZP)}

The mean PS, PDI, and ZP of prepared nanoparticles diluted in Milli- $Q^{\mathrm{TM}}$ water were measured using an ELSZ-1000 ZP and PS analyzer (Photal Otsuka Electronics, Tokyo, Japan), based on the dynamic light scattering method, at a fixed scattering angle of $90^{\circ}$ at 25 ${ }^{\circ} \mathrm{C}$. All measurements were performed in triplicate.

\section{Morphological analysis}

A few drops of the HA-CZ-SLN nanoparticle dispersion, diluted 10 -fold, were incubated with 2 $\%(w / v)$ phosphotungstic acid for $15 \mathrm{~min}$. The sample was subsequently placed on a copper grid and dried at ambient temperature. Sample grids were examined using TEM to view the morphology of nanoparticles.

\section{Encapsulation and loading efficiency}

Drug entrapment and loading efficiency were calculated from the ratio of the drug entrapped in the nanoparticles to the total amount of drug. Briefly, drug-loaded complexes were filtered using Amicon centrifugal filters at $5000 \mathrm{rpm}$ for $15 \mathrm{~min}$. The unencapsulated drug (CZ) in the filtrate was analyzed by HPLC UV detection at $280 \mathrm{~nm}$, using a mobile phase of acetonitrile and water at a 60:40 ratio and a flow rate of 1 $\mathrm{mL} / \mathrm{min}$. A standard curve was plotted for $\mathrm{CZ}$. The encapsulation efficiency (E) and loading efficiency (L) were calculated by Equations 1 and 2 , respectively.

$E(\%)=\{(\mathrm{Ct}-\mathrm{Cf}) / \mathrm{Ct}\} 100$ 
$L(\%)=\{(\mathrm{Ct}-\mathrm{Cf}) / \mathrm{W}\} 100$

where $\mathrm{Ct}, \mathrm{Cf}$, and $\mathrm{W}$ are the total amount of $\mathrm{CZ}$, the amount of free $\mathrm{CZ}$, and the total weight of the nanoparticles, respectively.

\section{In vitro release studies}

To evaluate the release of $\mathrm{CZ}$ from CZ-SLNs and $\mathrm{HA}$-CZ-SLNs, $1 \mathrm{mg} / \mathrm{mL}$ of the drug-loaded nanoparticles was incubated in $10 \mathrm{~mL}$ phosphate buffer solution (PBS, pH 7.4, ionic strength 0.1 $\mathrm{M}$, with $0.2 \%$ Tween 80 ) in a dialysis bag (molecular cut-off of $3.5 \mathrm{kDa}$ ) at $37{ }^{\circ} \mathrm{C}$ under gentle magnetic stirring (100 rpm). At fixed intervals, $1 \mathrm{~mL}$ of the supernatant was removed and replaced with fresh buffer solution to maintain a sink condition. CZ released in the collected samples was extracted with acetonitrile and determined by HPLC as described above. All experiments were performed in triplicate.

\section{Cell culture}

MCF-7 cells were obtained from the American Type Culture Collection (Manassas, USA), and the cells were cultured in DMEM supplemented with $10 \% \mathrm{FBS}$ and $5 \%$ penicillin/streptomycin. Cells were maintained at $37^{\circ} \mathrm{C}$ and $5 \% \mathrm{CO}_{2}$ in a humidified incubator.

\section{MTT assay}

Cell viability following treatment with the individual formulations was determined by MTT assay. Cells $\left(1 \times 10^{4}\right)$ were seeded into 96-well plates in $0.1 \mathrm{~mL}$ growth medium and incubated for $24 \mathrm{~h}$. Cells were then treated with the drug formulations (CZ, CZ-SLNs, and HA-CZ-SLNs) at $0.01-50 \mu \mathrm{g} / \mathrm{mL}$ or with control formulations (SLNs and HA-SLNs) at $0.1-1000 \mu \mathrm{g} / \mathrm{mL}$. All formulations were incubated for $48 \mathrm{~h}$, washed twice with PBS, treated with MTT solution (5 $\mathrm{mg} / \mathrm{mL}$ ), and incubated for another $3 \mathrm{~h}$. The resultant formazan crystals were dissolved in 100 $\mu \mathrm{L}$ DMSO. The mixture was gently shaken in a microplate reader before measuring the absorbance at $570 \mathrm{~nm}$.

\section{Flow cytometry}

MCF-7 cells $\left(2 \times 10^{5}\right)$ were seeded in 6-well plates and incubated for $24 \mathrm{~h}$ at $37^{\circ} \mathrm{C}$. Cultures were pretreated with or without HA $(100 \mu \mathrm{L}, 1$ $\mathrm{mg} / \mathrm{mL}$ ) for $15 \mathrm{~min}$ and further treated with the HA-CZ-SLN formulations for $30 \mathrm{~min}$. The cells were washed twice with PBS, trypsinized, centrifuged, and resuspended in PBS prior to analysis on a FACS flow cytometer (Becton Dickinson, US).

\section{Statistical analysis}

All experiments were performed in triplicate, and results are presented as mean \pm SD. Student's ttest was used to compare differences between groups, with $p<0.05$ considered to indicate statistical significance. Statistical evaluation was performed using Mann-Whitney $U$ test with the aid of SPSS Statistics 20.0 program (SPSS Inc., Chicago, IL, USA).

\section{RESULTS}

\section{Characteristics of HA-CZ-SLNs}

A schematic illustration of the HA-CZ-SLNs prepared by a high-pressure homogenization method is shown in Figure 1. The solid lipid core was prepared with compritol and DDAB (Didodecyldimethylammonium bromide), with Tween 80 added as a cationic lipid and surfactant. These lipids and tocopheryl polyethylene glycol succinate TPGS molecules were embedded as phospholipid molecules, which reduce leakage of the active therapeutic moiety from the nanoparticle. A mixture of $\mathrm{CZ}$, compritol, DDAB, and TPGS was dissolved in ethanol and preheated at $45{ }^{\circ} \mathrm{C}$ under continuous stirring to form an oil-in-water emulsion.
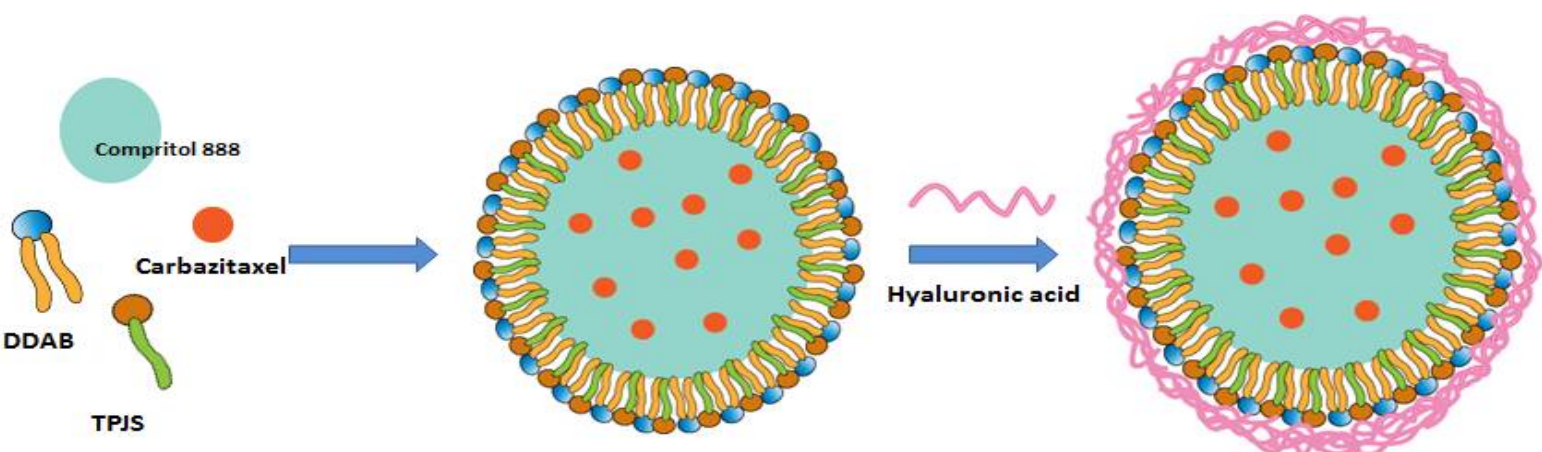

Figure 1: Schematic illustration of surface-functionalized hyaluronic acid-coated cabazitaxel-loaded solid lipid nanoparticles (HA-CZ-SLNs) 
This emulsion was homogenized for $5 \mathrm{~min}$ and sonicated at $70 \%$ amplitude for $5 \mathrm{~min}$. Figure $2 \mathrm{a}$ and Figure $2 \mathrm{~b}$ show that the average PS of the CZ-SLNs was $187.8 \pm 3.41 \mathrm{~nm}$, with strong positive charges averaging $41.7 \pm 2.13 \mathrm{mV}$ and a PDI of 0.13 , due to the presence of cationic lipids. Furthermore, the outer surface of the lipid nanoparticle was coated with HA via electrostatic interactions, increasing the particle size to 221.6 $\pm 2.67 \mathrm{~nm}$ and converting to a strong negative charge: $-20.7 \pm 1.12 \mathrm{mV}$ (Figure $2 \mathrm{c}$ and Figure 2d).

CZ was loaded into the hydrophobic core, and the encapsulation efficiency was determined by HPLC at $72.31 \pm 2.41 \%$, with a loading capacity of $4.41 \pm 1.41 \%$. Lastly, the particles were freeze-dried and stored at $4^{\circ} \mathrm{C}$. The morphology of the optimized HA-CZ-SLNs was revealed by TEM imaging, as shown in Figure 3.

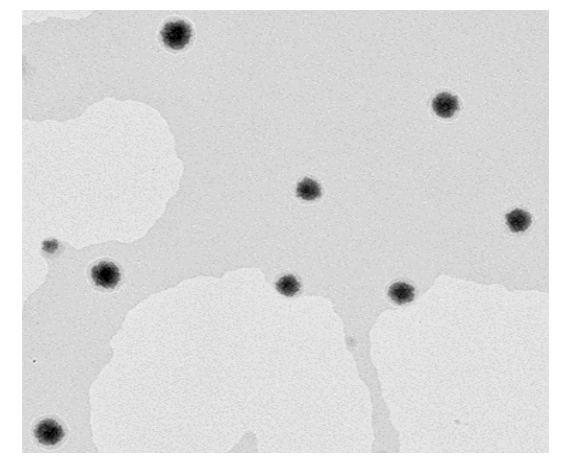

Figure 3: TEM image of the HA-CZ-SLNs
These images represent narrow spherical particles, with compact cores. The shell structures were observed as a layer on the core after coating the surfaces with HA, consistent with the dynamic light scattering data.

\section{In vitro drug release}

The in vitro release profile of $C Z$ from CZ-SLN and HA-CZ-SLN formulations was examined by dialysis. As illustrated in Figure 4, release from CZ-SLNs followed a biphasic pattern, with an initial burst release of $42 \%$ within $8 \mathrm{~h}$, followed by a sustained release of $65 \%$ over $48 \mathrm{~h}$. HACZ-SLNs followed a monophasic release pattern, with approximately 31.4 and $42 \%$ released by 12 and $48 \mathrm{~h}$, respectively. The burst release was due to the loose association between the drug and lipid, and the drug loaded into the core underwent further sustained release. In the case of HA-CZ-SLNs, the slower release rate was due to incorporation of $C Z$ into the inner core of SLN, protected by the exterior HA layer on the surface, which acts as a barrier to enable sustained and stable drug release throughout the time course.

\section{Cytotoxicity}

The effects of the different formulations on cell viability were investigated in MCF-7 cells by MTT assay (Figure 5). The drug-free SLNs and HASLNs at concentrations of $0.1-1000 \mu \mathrm{g} / \mathrm{mL}$ showed acceptable cell viability of $85 \%$ after 24 $\mathrm{h}$ of exposure, indicating that the carrier has excellent biocompatibility.

(c)

(a)

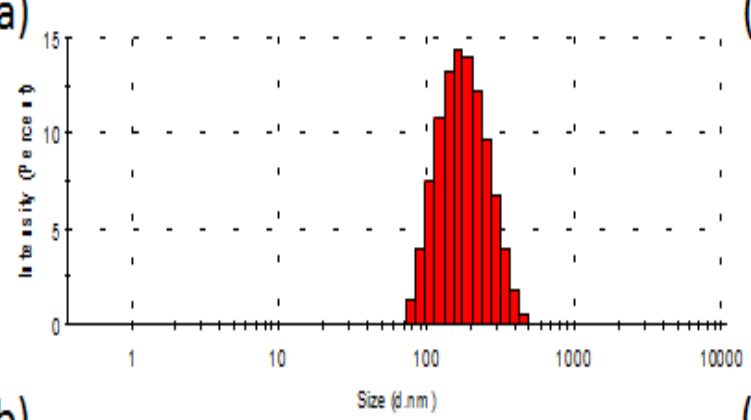

(b)

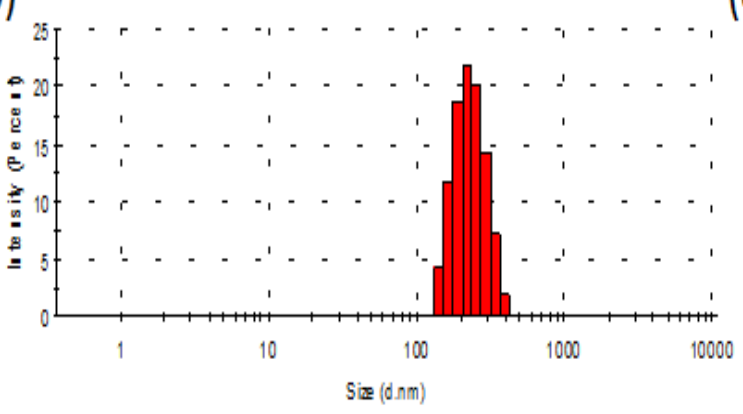

(d)
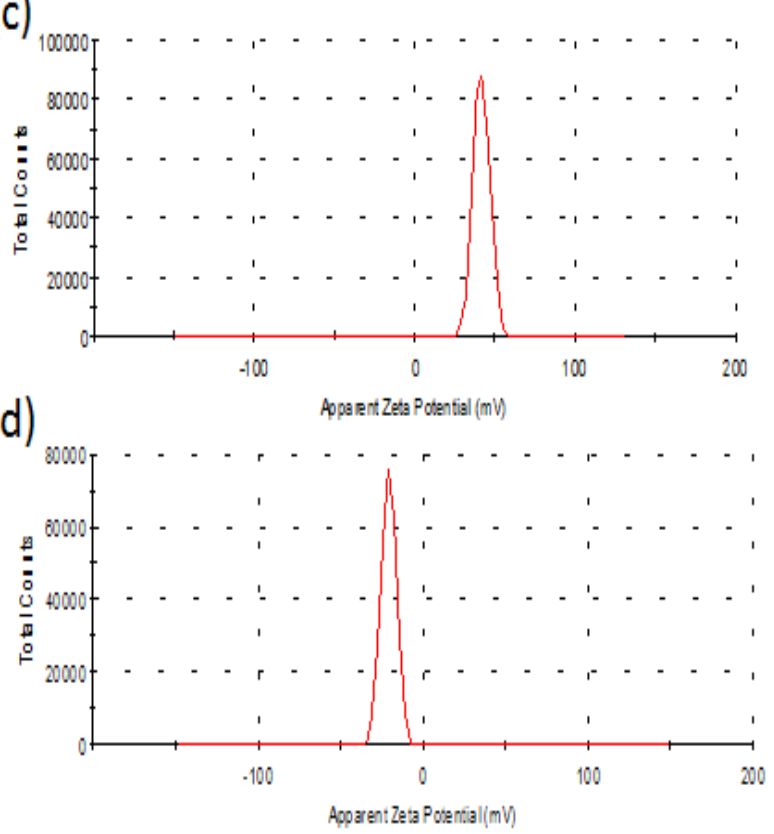

Figure 2: Dynamic light scattering characterization of particle size (a, b) and zeta potential $(c, d)$ of CZ-SLNs and HA-CZ-SLNs, respectively 


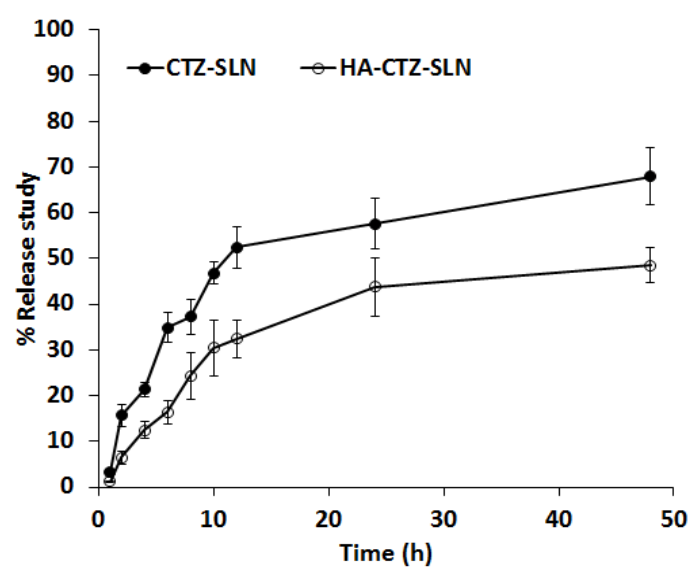

Figure 4: In vitro release study of CZ-SLNs and HACZ-SLNs, respectively, in PBS

Treatment with $1 \mu \mathrm{g} / \mathrm{mL}$ HA-CZ-SLNs exhibited significantly higher toxicity, with only $45 \%$ cell viability after treatment, compared with $68 \%$ viability after treatment with free $\mathrm{CZ}$. This indicates enhanced internalization by CD44 receptor-mediated endocytosis and subsequent induction of apoptosis. These data further indicate that HA-CZ-SLNs are more effective in inducing cell toxicity, even at higher concentrations of the free drug.

\section{Cellular uptake}

The internalization of HA-CZ-SLNs was evaluated in MCF-7 cells by flow cytometry (Figure 7). The results clearly demonstrate increased uptake of HA-CZ-SLNs compared with the controls, due to the interaction of HA with CD44. In addition, cells pre-treated with excess free HA for $1 \mathrm{~h}$ before exposure to HA-CZ-SLNs showed slightly reduced intracellular fluorescence intensity.

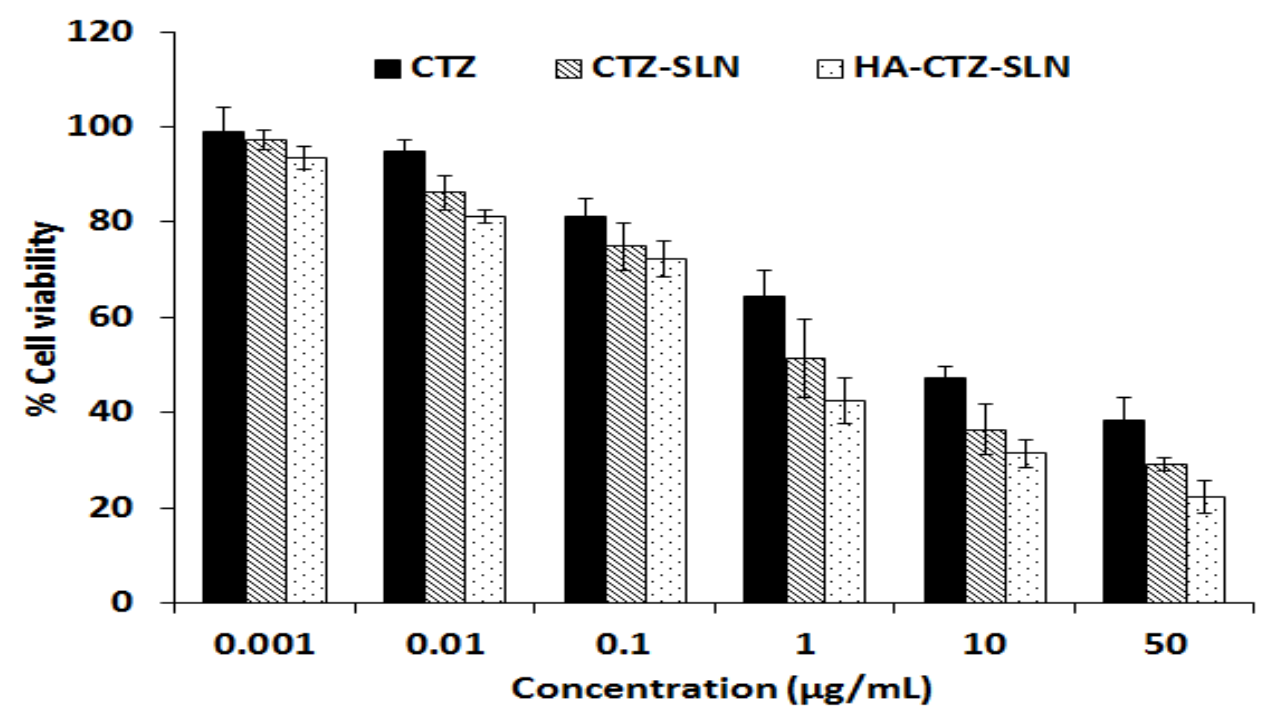

Figure 5: In vitro cytotoxicity of free CZ, CZ-SLNs, and HA-CZ-SLNs after incubation for $24 \mathrm{~h}(\mathrm{n}=6)$

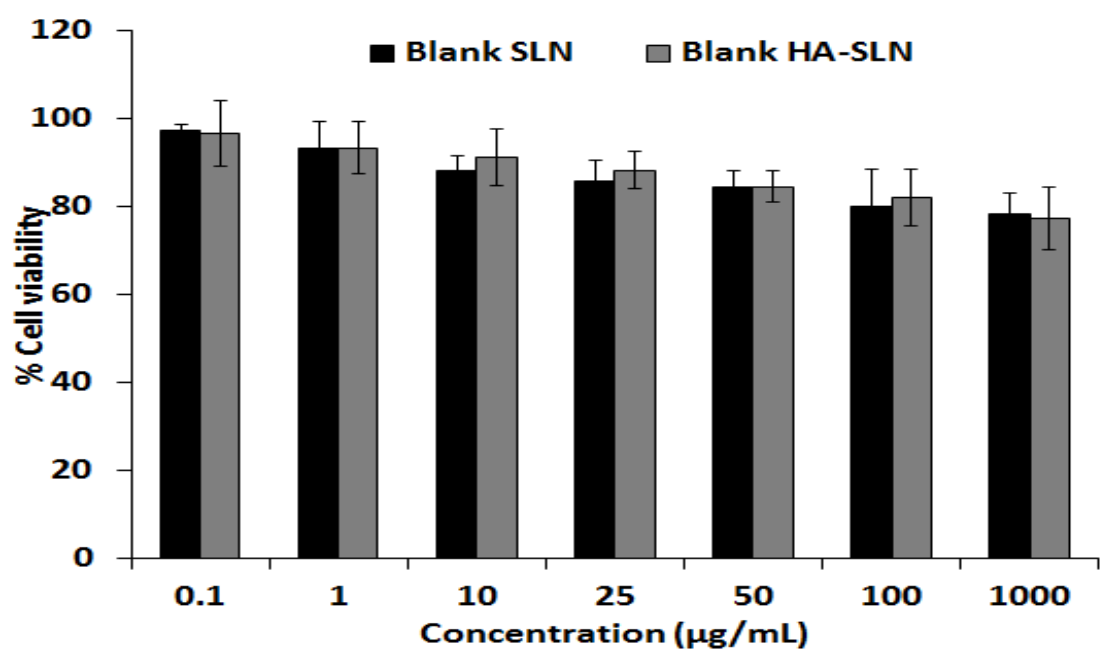

Figure 6: In vitro cytotoxicity of control SLNs and HA-SLNs at various concentrations after incubation for $24 \mathrm{~h}$ (n $=6)$ 


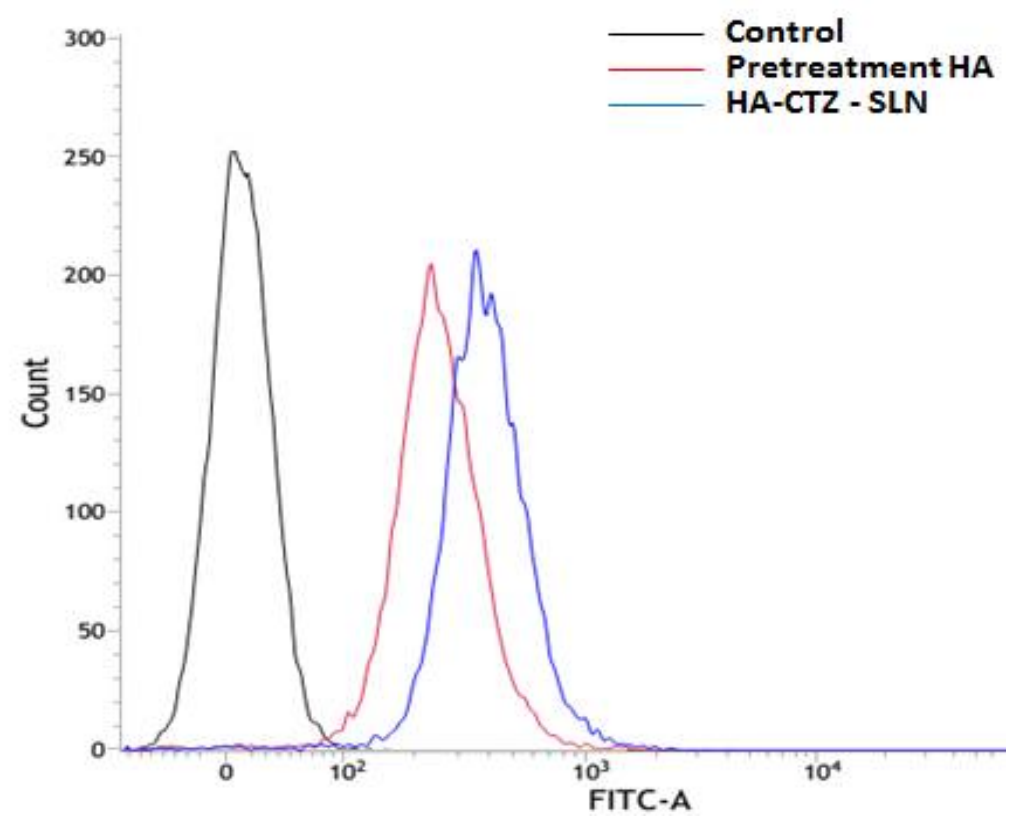

Figure 7: Intracellular uptake of HA-CZ-SLNs and the effects of $1 \mathrm{~h}$ pre-treatment with excess HA in CD44overexpressing MCF-7 cells

These results indicated significantly higher uptake of HA-CZ-SLNs, which were bound to the overexpressed CD44 receptors on MCF-7 cells and internalized via receptor-mediated endocytosis. This was remarkably diminished after HA pretreatment, independent of the charge on the surface $[17,18]$.

\section{DISCUSSION}

CZ, which has been approved by the U.S. Food and Drug Administration, is used clinically at various dilutions for intravenous administration. $\mathrm{CZ}$ has the advantage of overcoming multidrug resistance due to its poor affinity, compared with other taxane members such as docetaxel and paclitaxel, for P-glycoprotein, which pumps intracellular drugs out of cells [9]. However, there are drug stability problems with $\mathrm{CZ}$, as well as adverse effects, especially neutropenia. Therefore, biocompatible nanosystems, such as SLNs, have been designed to improve the delivery of $\mathrm{CZ}$, with enhanced permeability and retention effects and the ability to target tumors by CD44 receptor-mediated endocytosis of HA. Compared with other nano-delivery systems, SLNs exhibit many advantages, including easier preparation, improved stability, and component material safety. Hence, we developed surfacemodified CZ-loaded SLNs for the treatment of breast cancer. Coating the SLNs with HA led to significantly greater accumulation in tumorbearing lung tissue than was seen with uncoated SLNs. Coating by electrostatic attraction is a simple and controllable method that precludes using the chemical reactions and organic solvents needed to attach HA covalently to nanoparticles. Due to the high tumor specificity and biocompatibility properties of high-molecularweight $\mathrm{HA}$, we designed optimized HA-CZ-SLNs that mediated more efficient cellular uptake and facilitated delivery of anticancer drugs such as CZ to specific tumor cells (CD44+).

The rate of drug release from CZ-SLNs follows a biphasic pattern, with an initial burst release followed by sustained release, whereas that from HA-CZ-SLNs follows a monophasic release pattern. The burst release pattern is the result of the drug loaded loosely into the lipid, and further sustained release is the result of the drug loaded into the core. The toxicity of the drug-free carrier is negligible because of its highly biocompatible nature. The observed $20 \%$ carrier toxicity is caused by the cationic lipid, which promotes cell degradation. In addition, the cytotoxic effects of various formulations, such as free CZ, CZ-SLN, and HA-CZ-SLNs, exhibited a typical concentration-dependent cytotoxicity after $24 \mathrm{~h}$ of incubation. Drug-containing particles showed enhanced cellular $\mathrm{CZ}$ retention and intracellular acid-responsive drug release, resulting in disruption of $\beta$-tubulin in the G2/M phase, cell death via apoptosis, and enhanced cytotoxicity [19]. Increased uptake of HA-CZ-SLNs compared with control preparations was caused by the interaction of $\mathrm{HA}$ with CD44. Cells pre-treated with excess free HA for $1 \mathrm{~h}$ before HA-CZ-SLN 
treatment showed slightly reduced intracellular fluorescence intensity. These results indicate that the significantly higher uptake of HA-CZ-SLNs was caused by binding of the overexpressed CD44 receptors on MCF-7 cells and to receptormediated endocytosis, which could be inhibited by binding competition by free HA, independent of surface charge.

\section{CONCLUSION}

Surface-functionalized CZ-loaded lipid nanoparticles for breast cancer therapy have been prepared using HA. The in vitro profiles indicate sustained release of the nanoparticles. In addition, the encapsulated $\mathrm{CZ}$ show higher cytotoxicity against MCF-7 cells than did free CZ. The significantly increased internalization observed is the result of the HA layer that interacted with the CD44 receptor overexpressed on cancer cells. Thus, HA-CZ-SLNs are an excellent lipid-based formulation with enhanced antitumor activity and hence a potential candidate for breast cancer therapy.

\section{DECLARATIONS}

\section{Acknowledgement}

The authors would like to thank Dr. Chuan-guo An, Head of the Department of Breast and Thyroid Surgery, who offered valuable suggestions on the experiments and manuscript review. The authors acknowledge the People's Hospital of Rizhao for providing funds and lab facilities for this research.

\section{Conflict of Interest}

No conflict of interest associated with this work.

\section{Contribution of Authors}

The authors declare that this work was done by the authors named in this article and all liabilities pertaining to claims relating to the content of this article will be borne by them.

\section{Open Access}

This is an Open Access article that uses a funding model which does not charge readers or their institutions for access and distributed under the terms of the Creative Commons Attribution License (http://creativecommons.org/licenses/by/ 4.0) and the Budapest Open Access Initiative (http://www.budapestopenaccessinitiative.org/rea d), which permit unrestricted use, distribution, and reproduction in any medium, provided the original work is properly credited.

\section{REFERENCES}

1. Deng $X$, Cao M, Zhang J, Hu K, Yin Z, Zhou Z, Xiao X, Yang $Y$, Sheng $W, W u Y$, et al. Hyaluronic acid-chitosan nanoparticles for co-delivery of MiR-34a and doxorubicin in therapy against triple negative breast cancer. Biomater 2014; 35: 4333-4344.

2. Ferlay J, Soerjomataram I, Dikshit R, Eser S, Mathers C, Rebelo M, Parkin DM, Forman D, Bray F. Cancer incidence and mortality worldwide: sources, methods and major patterns in GLOBOCAN 2012. Int $J$ Cancer 2015; 136: 359-386.

3. Hess KR, Varadhachary GR, Taylor SH, Wei W, Raber MN, Lenzi R, Abbruzzese JL. Metastatic patterns in adenocarcinoma. Cancer 2006; 106: 1624-1633.

4. Bernard W. Stewart CPW. World cancer report 2014 ed. World Health Organization, 2014.

5. Wan $X$, Zheng $X$, Pang $X$, Pang Z, Zhao J, Zhang Z, Jiang $T, X u W$, Zhang $Q$, Jiang $X$. Lapatinib-loaded human serum albumin nanoparticles for the prevention and treatment of triple-negative breast cancer metastasis to thebrain.Oncotarget2016; 7: 3403834051.

6. Rowinsky M, Eric K. The development and clinical utility of the taxane class of antimicrotubule chemotherapy agents. Ann Rev Med 1997; 48: 353-374.

7. de Weger VA, Beijnen JH, Schellens JH. Cellular and clinical pharmacology of the taxanes docetaxel and paclitaxel--a review. Anticancer Drugs 2014; 25: 488494.

8. Lee SY, Kim S, Tyler JY, Park K, Cheng JX. Bloodstable, tumor-adaptable disulfide bonded mPEG-(Cys) 4-PDLLA micelles for chemotherapy. Biomater 2013; 34: 552-561.

9. de Bono JS, Oudard S, Ozguroglu M, Hansen S, Machiels JP, Kocak I, Gravis G, Bodrogi I, Mackenzie MJ, Shen L, et al. Prednisone plus cabazitaxel or mitoxantrone for metastatic castration-resistant prostate cancer progressing after docetaxel treatment: a randomised open-label trial. Lancet 2010; 376: 1147-1154.

10. Pivot $X$, Koralewski $P$, Hidalgo JL, Chan A, Goncalves A, Schwartsmann G, Assadourian S, and Lotz JP. A multicenter phase II study of XRP6258 administered as a 1-h i.v. infusion every 3 weeks in taxane-resistant metastatic breast cancer patients. Ann Oncol 2008; 19 : 1547-1552.

11. Galsky MD, Dritselis A, Kirkpatrick $P$, Oh WK. Cabazitaxel. Nat Rev Drug Discov 2010; 9: 677-678.

12. Cortes JE, Pazdur RJ. Docetaxel. J Clin Oncol 1995; 13 : 2643-2655.

13. Prokop A, Davidson JM. Nanovehicular intracellular delivery systems. J Pharm Sci 2008; 97: 3518-3590. 
14. Wissing SA, Kayser O, Muller RH. Solid lipid nanoparticles for parenteral drug delivery. Adv Drug Deliv Rev 2004; 56: 1257-1272.

15. Souto EB, Muller RH. Cosmetic features and applications of lipid nanoparticles (SLN, NLC). Int J Cosmet Sci 2008; 30: 157-165.

16. Shen H, Shi S, Zhang Z, Gong T, Sun X. Coating Solid Lipid Nanoparticles with Hyaluronic Acid Enhances Antitumor Activity against Melanoma Stem-like Cells. Theranostics 2015; 5: 755-771.

17. Luan J, Zhang D, Hao L, Qi L, Liu X, Guo H, Li C, Guo Y, $L i T$, Zhang $Q$. Preparation, characterization and pharmacokinetics of Amoitone B-loaded long circulating nanostructured lipid carriers. Colloids Surf $B$ Biointerfaces2014; 114: 255-260.

18. Ruttala HB, Ramasamy T, Poudal BK, Choi Y, Choi JY, Kim J, Ku SK, Choi HG, Yong CS, Kim JO. Molecularly targeted co-delivery of a histone deacetylase inhibitor and paclitaxel by lipid-protein hybrid nanoparticles for synergistic combinational chemotherapy. Oncotarget 2017; 8: 14925-14940.

19. Ruttala HB, Ramasamy T, Shin BS, Choi HG, Yong CS, Kim JO. Layer-by-layer assembly of hierarchical nanoarchitectures to enhance the systemic performance of nanoparticle albumin-bound paclitaxel. Int $J$ Pharm 2017; 519: 11-21. 